\title{
Desenvolvimento e caracterização de iogurtes de tapioca
}

\author{
Emanuel Neto Alves de Oliveira ${ }^{\mathrm{a}}$, Dyego da Costa Santos ${ }^{\mathrm{b} *}$, Rossana Maria Feitosa de Figueirêdo ${ }^{\mathrm{c}}$, \\ Regilane Marques Feitosa ${ }^{\mathrm{d}}$
}

\author{
${ }^{\text {a }}$ Instituto Federal do Rio Grande do Norte, Brasil \\ ${ }^{\mathrm{b}}$ Instituto Federal do Acre, Brasil \\ ${ }^{\mathrm{c}}$ Universidade Federal de Campina Grande, Brasil \\ ${ }^{\mathrm{d}}$ Instituto Federal de Alagoas, Brasil \\ *Autor correspondente (dyego.csantos@gmail.com)
}

\section{N F O}

\section{Keywords}

fermented milk quality control sensory acceptance

Palavras-chaves leite fermentado controle de qualidade aceitação sensorial

\begin{abstract}
A B S T R A C T
Development and characterization of tapioca yogurts.

Traditionally fruits are used to impart flavor and aroma in yogurts, however the dairy market requires innovation in order to attract and satisfy a greater number of consumers. An alternative to diversify the "presentation" of these products is the incorporation of unconventional ingredients, like tapioca. The objective of this work was to prepare yogurts with added tapioca with different concentrations $(0,7,14$ and $21 \%$ ) and to evaluate the physical, chemical, microbiological and sensory. It was observed that increasing the concentration tapioca promoted significant reductions in moisture content, proteins, lipids, lactose and acidity values and the increase in the ash, carbohydrates, calories, total solids and $\mathrm{pH}$. Was not detected the presence of total coliforms, thermotolerant coliforms, coagulase positive Staphylococcus or Salmonella spp. at the samples. The sensory attributes evaluated by the tasters showed scores higher than 6.0 (like slightly) for formulations with $0 \%$ (default) and 7\% tapioca, and scores below 5.0 (neither liked and / or disliked or) for yogurts with 14 and $21 \%$ tapioca. The purchase intent score was above 3.0 (maybe buy / might not buy) only in standard formulations and $7 \%$ tapioca, which also showed acceptability index higher than $70 \%$. Yoghurt with $7 \%$ tapioca was the sample that showed characteristics more similar yogurt, besides being the most preferred second sensory tests.
\end{abstract}

\section{R E S U M O}

Tradicionalmente as frutas são utilizadas para conferir aroma e sabor em iogurtes, entretanto o mercado de produtos lácteos requer inovações a fim de atrair e satisfazer um maior número de consumidores. Uma alternativa para diversificar a "apresentação" desses produtos é a incorporação de ingredientes não convencionais, a exemplo da tapioca. Objetivou-se com este trabalho elaborar iogurtes adicionados de diferentes concentrações de tapioca $(0,7,14$ e $21 \%)$ e avaliar as características físicas, químicas, microbiológicas e sensoriais. Observou-se que o aumento da concentração de tapioca promoveu reduções significativas nos teores de umidade, proteínas, lipídeos, lactose e acidez, e elevação significativa nos valores de cinzas, carboidratos, calorias, extrato seco total e pH. Não foi detectada a presença de coliformes totais, coliformes termotolerantes, Staphylococcus coagulase positiva ou Salmonella spp. nas amostras. Os atributos sensoriais avaliados pelos provadores revelaram escores superiores a 6,0 (gostei ligeiramente) para as formulações com $0 \%$ (padrão) e 7\% de tapioca, e escores inferiores a 5,0 (nem gostei e/ou nem desgostei) para os iogurtes com 14 e $21 \%$ de tapioca. A pontuação da intenção de compra foi acima de 3,0 (talvez comprasse/talvez não comprasse) apenas nas formulações padrão e com $7 \%$ de tapioca, que também apresentaram índice de aceitabilidade superior a 70\%. O iogurte com 7\% de tapioca foi a amostra que apresentou as características mais semelhantes do iogurte natural, além de ser o mais preferido segundo testes sensoriais. 


\section{INTRODUÇÃO}

O leite é um alimento natural, reconhecido por seu valor nutritivo, sendo considerado um alimento completo. Possui proteínas fundamentais à nutrição, com função plástica de reparação celular, além de fornecer aminoácidos essenciais em quantidade adequada para o crescimento do indivíduo e suplementação de dietas alimentares (Badaró et al., 2007). O leite pode ser consumido in natura ou processado como queijos, manteigas, doces e leites fermentados.

Dentre os leites fermentados, o iogurte vem se tornando mais popular devido ao modo de vida da população, sendo incluído na rotina diária por ser prático e de fácil consumo, além da imagem positiva de alimento saudável e nutritivo (Queiroga et al., 2011), constituindo-se uma importante fonte de proteínas, cálcio, fósforo, vitaminas e carboidratos (Ferreira et al., 2001). De acordo com a legislação brasileira em vigor (Brasil, 2007), iogurte é o produto cuja fermentação se realiza com cultivos de Streptococcus salivarius subsp. thermophilus e Lactobacillus delbrueckii subsp. bulgaricus, os quais podem ser acompanhados, de forma complementar, de outras bactérias acidolacticas, que, por sua atividade, contribuam nas características do produto final.

Tradicionalmente as frutas são muito utilizadas em iogurtes para conferir aroma e sabor, entretanto, com o intuito de satisfazer as mais variadas preferências e diversificar a forma de apresentação desse derivado lácteo, sugere-se a utilização de outros ingredientes não convencionais, como produtos típicos e populares da culinária brasileira, a exemplo da tapioca. Silveira et al. (2009) relataram que a tapioca é um dos principais produtos da culinária das regiões Norte e Nordeste do Brasil, sendo utilizado em vários pratos da gastronomia, inclusive na produção de produtos lácteos como sorvetes. Nessas regiões o sorvete de tapioca é uma sobremesa muito apreciada por moradores e principalmente por turistas que buscam características regionais na culinária.

A qualidade de um alimento implica, entre outros fatores, na satisfação do consumidor. Um produto deve, além de possuir excelentes características físicas e químicas, apresentar características sensoriais que atendam às necessidades e anseios do consumidor (Minim, 2006). Segundo Jaeger (2006), as características sensoriais do alimento, como sabor, aroma, aparência e textura são primordiais para direcionar o futuro consumidor em uma aceitação positiva do produto. Nesse sentido, faz-se necessário o estudo não apenas de atributos nutricionais, físicos e químicos de iogurtes adicionados de tapioca, mas também de aspectos microbiológicos e sensoriais para verificar a viabilidade de produção desse novo produto.

Na literatura estão disponíveis vários estudos envolvendo o processamento de iogurtes com a utilização de uma grande variedade de ingredientes, a exemplos de polpa de frutas (Mesquita et al., 2012; Loures et al., 2010; Oliveira et al., 2008), geleia de frutas (Queiroga et al., 2011; Oliveira et al., 2011), xarope de frutas (Borges et al., 2009; Rocha et al., 2008), mel (Freitas et al., 2012), extrato de ervas (Preci et al., 2011), café instantâneo (Mathias et al., 2011) e amêndoas (Cavalcante et al., 2009), no entanto não existem relatos acerca da utilização de tapioca em iogurtes, fato este que justifica a realização deste estudo.

Esta pesquisa teve como objetivo elaborar iogurtes adicionados de diferentes concentrações de tapioca e avaliar as características físicas, químicas, microbiológicas e sensoriais dos produtos processados.

\section{MATERIAL E MÉTODOS}

O leite integral utilizado na elaboração dos iogurtes foi proveniente de um pequeno produtor da cidade de Campina Grande (PB). Após a recepção, o leite foi filtrado em peneiras de nylon e submetido a uma pasteurização lenta à temperatura de $65{ }^{\circ} \mathrm{C}$ por 30 minutos. Em seguida, procedeu-se o resfriamento do leite até a temperatura de $45^{\circ} \mathrm{C}$ e adicionou-se $5 \%$ de leite em pó integral, $10 \%$ de açúcar e $1 \%$ de cultura láctica contendo os micro-organismos S. thermophilus e L. bulgaricus, preparada seguindo-se as recomendações do fabricante. A mistura foi incubada a $45^{\circ} \mathrm{C}$ por $8 \mathrm{~h}$, até que se atingisse $\mathrm{pH}$ de aproximadamente 4,7. Posteriormente o iogurte foi resfriado lentamente até $10{ }^{\circ} \mathrm{C}$ e estocado em câmara fria durante 12 horas.

Após maturação, a massa do iogurte foi batida e separada em quatro tratamentos: iogurte sem adição de tapioca (padrão), e iogurtes adicionados de 7, 14 e $21 \%$ de tapioca $\left(\mathrm{F}_{7 \%}, \mathrm{~F}_{14 \%}\right.$ e $\left.\mathrm{F}_{21 \%}\right)$. O iogurte padrão e os adicionados de tapioca foram envasados em garrafas de polipropileno de $500 \mathrm{~mL}$ e armazenados à $10^{\circ} \mathrm{C}$. Para processamento das tapiocas foi utilizada goma fresca adquirida no mercado varejista da cidade de Campina Grande, Paraíba. Uma fina camada de goma (cerca de $5 \mathrm{~mm}$ ) foi colocada em tacho aberto de inox aquecida em fogo brando até consistência gelatinosa e seca, sendo posteriormente desintegrada em liquidificador doméstico.

O leite, a tapioca e os iogurtes de tapioca (padrão, 7,14 e $21 \%$ ) foram analisados quanto à umidade, cinzas, lipídios, acidez total titulável e pH segundo as normas do Instituto Adolfo Lutz (IAL, 2008); proteínas e carboidratos totais de acordo 
com metodologias da AOAC (2010); valor calórico segundo o Ministério da Saúde (Brasil, 2005) e cor utilizando espectrofotômetro portátil MiniScan HunterLab XE Plus, modelo $4500 \mathrm{~L}$, obtendo-se os seguintes parâmetros $\mathrm{L}^{*}, \mathrm{a}^{*} \mathrm{e} \mathrm{b}^{*}$, em que $\mathrm{L}^{*}$ define a luminosidade $\left(\mathrm{L}^{*}=0\right.$ - preto e $\mathrm{L}^{*}=100$-branco) e $\mathrm{a}^{*}$ e b* são responsáveis pela cromaticidade $\left(+\mathrm{a}^{*}\right.$ vermelho; $-\mathrm{a}^{*}$ verde; $+\mathrm{b}^{*}$ amarelo; $-\mathrm{b}^{*}$ azul). O leite e os iogurtes foram ainda submetidos às determinações de lactose e extrato seco total (IAL, 2008).

Os iogurtes de tapioca foram analisados quanto aos parâmetros microbiológicos de coliformes totais $\left(35^{\circ} \mathrm{C}\right)$ e termotolerantes $\left(45^{\circ} \mathrm{C}\right)$, Staphylococcus coagulase positiva e Salmonella spp. de acordo com metodologias preconizadas pelo APHA (2001).

As diferentes formulações de iogurtes foram submetidas a teste de aceitação, com uso de escala hedônica mista de nove pontos, com escores variando de 1 (desgostei extremamente) à 9 (gostei extremamente), segundo Dutcosky (2011). O teste sensorial foi realizado com uma equipe de 40 provadores não treinados, composta por homens e mulheres com idades entre 19 e 58 anos. Os julgadores avaliaram atributos considerados importantes para a aceitação do produto, como aparência, cor, sabor, acidez, aroma, textura e impressão global. Os iogurtes foram servidos aos julgadores à $6{ }^{\circ} \mathrm{C}$, em copos plásticos codificados com números aleatórios de três dígitos, sendo fornecida ainda água mineral para limpeza do palato entre a avaliação das amostras. Paralelamente efetuou-se investigação da intenção de compra dos iogurtes, com uso de escala mista de cinco pontos, com escores variando de 1 (certamente não compraria) à 5 (certamente compraria). Na tabulação dos dados, calculou-se o índice de aceitabilidade (Equação 1), para todos os atributos avaliados pelos julgadores (Gularte, 2011). Os resultados dos índices de aceitabilidade para todos os atributos foram somados e divididos pelo número de atributos avaliados, com o intuito de se calcular o índice de aceitabilidade médio para cada iogurte.

$$
\text { Índice de aceitabili dade }(\%)=\frac{\mathrm{M}}{\mathrm{N}} \times 100
$$

em que:

M - média do somatório dos resultados dos julgadores;

$\mathrm{N}$ - número de pontos utilizados na escala de avaliação.

$\mathrm{Na}$ análise estatística dos dados físicos, químicos e sensoriais, utilizou-se o delineamento experimental inteiramente casualizado com quatro tratamentos e três repetições, utilizando-se o software Assistat. Os dados foram submetidos à análise de variância (ANOVA) e a comparação entre médias foi feita pelo teste de Tukey a $5 \%$ de probabilidade.

\section{RESULTADOS E DISCUSSÃO}

$\mathrm{Na}$ tabela 1 tem-se os resultados da caracterização fisica e química do leite e da tapioca utilizados no processamento dos iogurtes. O leite pasteurizado apresentou-se em conformidade com a legislação em vigor (Brasil, 2011), com mais de $3 \%$ de gordura, ácido lático compreendido entre 0,14 a $0,18 \%$ e conteúdo de proteína superior a $2,9 \%$. O conteúdo mineral (cinzas) apresentou-se inferior a $1 \%$. O leite apresentou conteúdo de lactose acima de $4 \%$ e com pH ligeiramente ácido. $\mathrm{O}$ extrato seco total foi superior a $10 \%$ e os parâmetros de cor evidenciaram alta luminosidade (claridade) e tonalidade amarelada, característica do produto. A tapioca apresentou baixo conteúdo de proteínas, lipídeos e minerais, sendo considerável a concentração de carboidratos, responssável pelo valor calórico superior a 330 $\mathrm{kcal} / 100 \mathrm{~g}$. A acidez da tapioca foi inferior a $6 \%, \mathrm{o}$ pH ácido, com os parâmetros de cor revelando mais de 80 de luminosidade $\left(\mathrm{L}^{*}\right)$ com tons amarelados $\left(+b^{*}\right)$.

Tabela 1 - Caracterização nutricional, física e química do leite e da tapioca utilizados no processamento dos iogurtes de tapioca.

\begin{tabular}{|c|c|c|}
\hline Parâmetro & Leite & Tapioca \\
\hline Umidade (\%) & 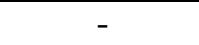 & $17,38 \pm 0,35$ \\
\hline Cinzas (\%) & $0,48 \pm 0,03$ & $0,82 \pm 0,04$ \\
\hline Lipídeos (\%) & $3,45 \pm 0,02$ & $0,79 \pm 0,03$ \\
\hline Proteínas $(\%)$ & $3,10 \pm 0,10$ & $0,10 \pm 0,02$ \\
\hline Carboidratos $(\%)$ & - & $80,91 \pm 0,41$ \\
\hline Valor calórico (kcal/100 g) & - & $331,15 \pm 1,38$ \\
\hline Acidez (\% ácido lático) & $0,16 \pm 0,01$ & $0,12 \pm 0,01$ \\
\hline $\mathrm{pH}$ & $6,30 \pm 0,02$ & $5,75 \pm 0,01$ \\
\hline Lactose (\%) & $4,35 \pm 0,05$ & - \\
\hline
\end{tabular}

Tabela 1 - Caracterização nutricional, física e química do leite e da tapioca utilizados no processamento dos 
iogurtes de tapioca (continuação).

\begin{tabular}{lcc}
\multicolumn{1}{c}{ Parâmetro } & Leite & Tapioca \\
\hline Extrato seco total $(\%)$ & $12,30 \pm 0,21$ & - \\
Luminosidade $\left(\mathrm{L}^{*}\right)$ & $85,25 \pm 0,13$ & $81,39 \pm 0,25$ \\
Intensidade de verde $\left(-\mathrm{a}^{*}\right)$ & $-1,74 \pm 0,09$ & $-0,08 \pm 0,02$ \\
Intensidade de amarelo $\left(+\mathrm{b}^{*}\right)$ & $12,36 \pm 0,09$ & $3,89 \pm 0,13$ \\
\hline
\end{tabular}

Têm-se na tabela 2 a composição nutricional e o valor calórico das diferentes formulações de iogurtes de tapioca. Observa-se que o conteudo de umidade variou de $70,30 \%\left(\mathrm{~F}_{21 \%}\right)$ a 80,25 (padrão), com esse parâmetro diminuindo significativamente $(\mathrm{p}<0,05)$ à medida que se aumentava a concentração de tapioca. Isso está relacionado ao teor de umidade relativamente baixo da tapioca
(Tabela 1), que promoveu, ao ser adicionado aos iogurtes, concentração de sólidos e consequentemente queda da umidade. Ao estudarem iogurtes contendo diferentes concentrações de sólidos totais, Mantovani et al. (2012) verificaram que o aumento dos sólidos totais promoveu reduções no teor de umidade, estando em acordo com o observado neste estudo.

Tabela 2 - Composição nutricional e valor calórico dos iogurtes de tapioca.

\begin{tabular}{ccccccc}
\hline Amostra & $\begin{array}{c}\text { Umidade } \\
(\boldsymbol{\%})\end{array}$ & $\begin{array}{c}\text { Cinzas } \\
(\mathbf{\%})\end{array}$ & $\begin{array}{c}\text { Lipídeos } \\
(\mathbf{\%})\end{array}$ & $\begin{array}{c}\text { Proteínas } \\
(\boldsymbol{\%})\end{array}$ & $\begin{array}{c}\text { Carboidratos } \\
(\boldsymbol{\%})\end{array}$ & $\begin{array}{c}\text { Calorias } \\
(\mathbf{k c a l} / \mathbf{1 0 0} \mathbf{g})\end{array}$ \\
\hline Padrão & $80,25^{\mathrm{a}}$ & $0,36^{\mathrm{d}}$ & $3,13^{\mathrm{a}}$ & $2,92^{\mathrm{a}}$ & $13,34^{\mathrm{d}}$ & $93,23^{\mathrm{d}}$ \\
$\mathrm{F}_{7 \%}$ & $77,62^{\mathrm{b}}$ & $0,41^{\mathrm{c}}$ & $2,77^{\mathrm{b}}$ & $2,87^{\mathrm{ab}}$ & $16,34^{\mathrm{c}}$ & $101,71^{\mathrm{c}}$ \\
$\mathrm{F}_{14 \%}$ & $75,19^{\mathrm{c}}$ & $0,51^{\mathrm{b}}$ & $2,01^{\mathrm{c}}$ & $2,50^{\mathrm{b}}$ & $19,78^{\mathrm{b}}$ & $107,24^{\mathrm{b}}$ \\
$\mathrm{F}_{21 \%}$ & $70,30^{\mathrm{d}}$ & $0,63^{\mathrm{a}}$ & $1,61^{\mathrm{d}}$ & $1,94^{\mathrm{c}}$ & $25,51^{\mathrm{a}}$ & $124,33^{\mathrm{a}}$ \\
\hline MG & 75,84 & 0,48 & 2,38 & 2,56 & 18,74 & 106,63 \\
DMS & 1,29 & 0,04 & 0,12 & 0,38 & 1,17 & 5,46 \\
CV $(\%)$ & 0,65 & 3,50 & 1,91 & 5,66 & 2,38 & 1,96 \\
Fcal & $220,63^{* *}$ & $160,40^{* *}$ & $690,20^{* *}$ & $29,32^{* *}$ & $410,60^{* *}$ & $118,65^{* *}$ \\
\hline
\end{tabular}

MG - Media geral; DMS - Desvio médio significativo; CV - Coeficiente de variação; Fcal - F calculado. Médias seguidas da mesma letra, na coluna, não diferem estaticamente a $5 \%$ de probabilidade pelo teste de Tukey; $* *$ - significativo a $1 \%$ de probabilidade pelo teste F.

O teor de cinzas nos iogurtes aumentou significativamente $(\mathrm{p}<0,05)$ com o aumento da concentração de tapioca. Este acréscimo foi de $75 \%$ no iogurte com $21 \%$ de tapioca $\left(\mathrm{F}_{21 \%}\right)$ quando comparado com o iogurte padrão. Observa-se que todos os valores das cinzas foram inferiores a 1,0\%. A pesar da elevação gradual nesses teores, nota-se que todos os valores apresentaram-se abaixo do conteudo mineral reportado por Mesquita et al. (2012), Queiroga et al. (2011) e Oliveira et al. (2011), ao estudarem iogurtes adicionados de produtos de frutas.

Quanto aos lipídeos, este foi reduzido significativamente $(\mathrm{p}<0,05)$ à medida que se aumentava a concentração de tapioca, corroborando com Chisté et al. (2012), que afirmaram que a tapioca é um alimento podre em lipídeos. De acordo com a legislação em vigor (Brasil, 2007), o iogurte padrão é classificado como integral, por possuir teor de gordura acima de $3 \%$, e os demais iogurtes $\left(\mathrm{F}_{7 \%}, \mathrm{~F}_{14 \% \mathrm{e}} \mathrm{F}_{21 \%}\right)$ são classificados como parcialmente desnatados, por apresentarem teor de gordura dentro da faixa de 0,6 a 2,9\%.

O conteúdo protéico nos iogurtes variou de 1,94 $\left(\mathrm{F}_{21 \%}\right)$ a $2,92 \%$ (padrão), com queda significativa $(p<0,05)$ desse parâmetro com o aumento da concentração de tapioca, uma vez que a tapioca apresentou teor de proteína muito inferior ao do leite (Tabela 1). Costa et al. (2012) verificaram comportamento oposto ao desenvolverem iogurte adicionado de juçaí (Euterpe edulis Martius), com elevação no conteúdo protéico a medida que se aumentava a concentração do vegetal.

Como esperado, os carboidratos aumentaram significativamente $(\mathrm{p}<0,05)$ com o aumento da concentração de tapioca, uma vez que este é constituído em grande parte por carboidratos (Tabela 1), em especial por amido (Chisté et al., 2012). A elevação gradual nos carboidratos promoveu aumento significativo no valor calórico dos iogurtes, atingindo na formulação com $21 \%$ de tapioca valor energético $33 \%$ superior à formulação padrão. Braga et al. (2012) reportaram para iogurtes adicionados de polpa e xarope de mangostão (Garcinia mangostana L.) valores calóricos dentro da faixa encontrada para os iogurtes de tapioca, no entanto Oliveira et al. (2011) encontraram valor calórico superior a $140 \mathrm{kcal} / 100 \mathrm{~g}$ em iogurte com geleia de açaí, valor este bem superior aos relatados neste estudo.

Na tabela 3 observam-se os dados físicos e químicos dos diferentes iogurtes de tapioca. Nota-se 
que o teor de lactose diminuiu significativamente $(\mathrm{p}<0,05)$ com o aumento da concentração de tapioca, justificado pela adição de material não lácteo, atingindo concentração inferior a $2 \%$ no iogurte contendo $21 \%$ de tapioca $\left(\mathrm{F}_{21 \%}\right)$. Também foi detectada redução significativa $(\mathrm{p}<0,05)$ nos valores de acidez, promovida pela adição da tapioca, o que diminui o conteudo de ácido lático em solução. Resultados semelhantes foram apontados por Oliveira et al. (2008) em iogurtes adicionados de diferentes concentrações de polpa de araticum, com tendencia de redução da acidez com o aumento da percentual da polpa. Todos os iogurtes, com exceção da formulação com $21 \%$ de tapioca $\left(\mathrm{F}_{21 \%}\right)$, apresentaram-se em conformidade com a legislação brasileira (Brasil, 2007), que estabelece valores de acidez compreendidos entre 0,6 e $1,5 \%$.

$\mathrm{O}$ pH nos iogurtes variou de 4,74 (padrão) a 5,01 $\left(\mathrm{F}_{21 \%}\right)$, com aumento significativo $(\mathrm{p}<0,05)$ desse parâmetro com o aumento da concentração de tapioca. Mantovani et al. (2012) também verificaram aumento nos valores de $\mathrm{pH}$ com o aumento de sólidos em iogurtes adicionados de goiaba. $\mathrm{O}$ extrato seco total aumentou significativamente com o aumento da concentração de tapioca, comportamento também verificado por Mantovani et al. (2012).

$\mathrm{Na}$ tabela 4 se apresentam os parâmetros de cor $\left(\mathrm{L}^{*},-\mathrm{a}^{*} \mathrm{e}+\mathrm{b}^{*}\right)$ dos iogurtes de tapioca. A luminosidade $\left(\mathrm{L}^{*}\right)$ diferiu estatisticamente $(\mathrm{p}<0,05)$ entre todas as formulações, contudo observou-se que todos os valores de $L^{*}$ foram acima de 80 , uma vez que a tapioca utilizada também é de natureza clara (Tabela 1). Os iogurtes apresentaram leve tom esverdeado $\left(-\mathrm{a}^{*}\right)$, sendo mais evidente a tonalidade amarelada (+b*). Preci et al. (2011) desenvolveram iogurtes light com extrato de erva-mate e encontraram parâmetros de cor semelhantes. Os autores reportaram valores de $\mathrm{L}^{*}$ superiores a 80 e valores de $-a^{*}$ compreendidos entre $-3,75$ e $-4,12$ e $+b$ variando de 4,40 a 12,61 .

Tabela 3 - Composição física e química de iogurtes de tapioca.

\begin{tabular}{ccccc}
\hline Amostra & Lactose (\%) & Acidez (\%) & pH & Extrato seco total (\%) \\
\hline Padrão & $2,63^{\mathrm{a}}$ & $0,78^{\mathrm{a}}$ & $4,74^{\mathrm{d}}$ & $19,75^{\mathrm{d}}$ \\
$\mathrm{F}_{7 \%}$ & $2,33^{\mathrm{b}}$ & $0,66^{\mathrm{b}}$ & $4,86^{\mathrm{c}}$ & $22,38^{\mathrm{c}}$ \\
$\mathrm{F}_{14 \%}$ & $2,00^{\mathrm{c}}$ & $0,62^{\mathrm{b}}$ & $4,93^{\mathrm{b}}$ & $24,81^{\mathrm{b}}$ \\
$\mathrm{F}_{21 \%}$ & $1,63^{\mathrm{d}}$ & $0,47^{\mathrm{c}}$ & $5,01^{\mathrm{a}}$ & $29,70^{\mathrm{a}}$ \\
\hline MG & 2,15 & 0,63 & 4,89 & 24,16 \\
DMS & 0,07 & 0,05 & 0,04 & 1,29 \\
CV $(\%)$ & 1,29 & 2,76 & 0,35 & 2,04 \\
Fcal & $717,06^{* *}$ & $163,99^{* *}$ & $137,56^{* *}$ & $220,63^{* *}$ \\
\hline
\end{tabular}

MG - Media geral; DMS - Desvio médio significativo; CV - Coeficiente de variação; Fcal - F calculado. Médias seguidas da mesma letra, na coluna, não diferem estaticamente a $5 \%$ de probabilidade pelo teste de Tukey; ** - significativo a $1 \%$ de probabilidade pelo teste F.

Tabela 4 - Parâmetros de cor dos iogurtes de tapioca.

\begin{tabular}{lccc}
\hline \multicolumn{1}{c}{ Amostra } & $\begin{array}{c}\text { Luminosidade } \\
\left(\mathbf{L}^{*}\right)\end{array}$ & $\begin{array}{c}\text { Intensidade de } \\
\text { verde (-a*) }\end{array}$ & $\begin{array}{c}\text { Intensidade de } \\
\text { amarelo (+b*) }\end{array}$ \\
\hline Padrão & $86,24^{\mathrm{b}}$ & $-2,89^{\mathrm{b}}$ & $9,72^{\mathrm{c}}$ \\
$\mathrm{F}_{7 \%}$ & $85,69^{\mathrm{c}}$ & $-2,63^{\mathrm{a}}$ & $9,20^{\mathrm{c}}$ \\
$\mathrm{F}_{14 \%}$ & $88,25^{\mathrm{a}}$ & $-3,22^{\mathrm{c}}$ & $13,36^{\mathrm{a}}$ \\
$\mathrm{F}_{21 \%}$ & $84,37^{\mathrm{d}}$ & $-2,64^{\mathrm{ab}}$ & $11,68^{\mathrm{b}}$ \\
\hline MG & 86,14 & $-2,85$ & 10,99 \\
DMS & 0,40 & 0,25 & 0,67 \\
CV $(\%)$ & 0,18 & 8,33 & 2,33 \\
Fcal. & $328,66^{* *}$ & $24,76^{* *}$ & $166,37^{* *}$ \\
\hline
\end{tabular}

MG - Media geral; DMS - Desvio médio significativo; CV - Coeficiente de variação; Fcal - F calculado. Médias seguidas da mesma letra, na coluna, não diferem estaticamente a $5 \%$ de probabilidade pelo teste de Tukey; ** - significativo a $1 \%$ de probabilidade pelo teste F.

Na tabela 5 estão apresentados os resultados das análises microbiológicas dos iogurtes de tapioca. Os parâmetros pesquisados mostraram ausência de coliformes totais e termotolerantes, Staphylococcus coagulase positiva e Salmonella spp., evidenciando que os iogurtes foram processados sob condições higiênico-sanitárias adequadas, no que diz respeito à manipulação das matérias-primas, utensílios e equipamentos utilizados para obtenção do produto final, estando apto para consumo humano, sem 
risco de causar toxinfecção alimentar (Oliveira et al., 2011), estando em conformidade com a legislação brasileira (Brasil, 2007). Braga et al. (2012), Costa et al. (2012), Oliveira et al. (2011) e Oliveira et al. (2008) reportaram resultados microbiológicos similares ao estudarem iogurtes adicionados de mangostão, juçaí, açaí e araticum, respectivamente.

Têm-se na Tabela 6 as médias dos atributos sensoriais avaliados nos iogurtes de tapioca. Todos os atributos sensoriais e a intensão de compra tiveram tendência significativa $(\mathrm{p}<0,05)$ de redução dos escores atribuidos pelos avaliadores a medida que se aumentava a concentração de tapioca, evidenciando que as respostas dos provadores sofreram influência da proporção de tapioca. Nota-se ainda que apenas as formulações padrão e $\mathrm{F}_{7 \%}$ apre- sentaram escores superiores a 6,0 (gostei ligeiramente) para todos os atributos, sendo que a formulação com $21 \%$ de tapioca revelou a maioria dos atributos com escores inferiores a 5,0 (nem gostei e/ou nem desgostei). A intenção de compra mostrou-se favorável apenas para os iogurtes padrão e com $7 \%$ de tapioca, já os demais iogurtes $\left(\mathrm{F}_{14 \%} \mathrm{e}\right.$ $\mathrm{F}_{21 \%}$ ) apresentaram escores inferiores a 3,0 (talvez comprasse/talvez não comprasse). Schimidt et al. (2012) encontraram em iogurtes de acerola tendência de redução dos escores atribuídos pelos provadores para os atributos de sabor, textura e aroma, ao aumentarem a concentração de polpa, comportamento este semelhante ao verificado nos iogurtes de tapioca.

Tabela 5 - Parâmetros microbiológicos dos iogurtes de tapioca.

\begin{tabular}{lccc}
\hline Amostra & $\begin{array}{c}\text { Coliformes totais e termotolerantes } \\
\text { (NMP/g) }\end{array}$ & $\begin{array}{c}\text { Staphylococcus coagulase posi- } \\
\text { tiva (UFC/g) }\end{array}$ & Salmonella spp. \\
\hline Padrão & $<3,0$ & $<10,0$ & Ausente \\
$\mathrm{F}_{7 \%}$ & $<3,0$ & $<10,0$ & Ausente \\
$\mathrm{F}_{14 \%}$ & $<3,0$ & $<10,0$ & Ausente \\
$\mathrm{F}_{21 \%}$ & $<3,0$ & $<10,0$ & Ausente \\
\hline
\end{tabular}

NMP - número mais provável; UFC - unidade formadora de colônia.

Tabela 6 - Médias dos atributos sensoriais avaliados nos iogurtes de tapioca.

\begin{tabular}{lcccccccc}
\hline Amostra & Aparência & Cor & Sabor & Acidez & Aroma & Textura & $\begin{array}{c}\text { Impressão } \\
\text { global }\end{array}$ & $\begin{array}{c}\text { Intenção } \\
\text { de compra }\end{array}$ \\
\hline Padrão & $7,05^{\mathrm{a}}$ & $7,58^{\mathrm{a}}$ & $7,68^{\mathrm{a}}$ & $7,50^{\mathrm{a}}$ & $7,45^{\mathrm{a}}$ & $6,97^{\mathrm{a}}$ & $7,29^{\mathrm{a}}$ & $4,13^{\mathrm{a}}$ \\
$\mathrm{F}_{7 \%}$ & $6,50^{\mathrm{ab}}$ & $7,08^{\mathrm{ab}}$ & $6,79^{\mathrm{ab}}$ & $6,97^{\mathrm{ab}}$ & $6,95^{\mathrm{ab}}$ & $6,37^{\mathrm{ab}}$ & $6,74^{\mathrm{ab}}$ & $3,50^{\mathrm{a}}$ \\
$\mathrm{F}_{14 \%}$ & $5,53^{\mathrm{b}}$ & $6,97^{\mathrm{ab}}$ & $6,11^{\mathrm{b}}$ & $6,16^{\mathrm{bc}}$ & $6,42^{\mathrm{ab}}$ & $5,50^{\mathrm{b}}$ & $5,95^{\mathrm{b}}$ & $2,76^{\mathrm{b}}$ \\
$\mathrm{F}_{21 \%}$ & $3,95^{\mathrm{c}}$ & $6,26^{\mathrm{b}}$ & $4,29^{\mathrm{c}}$ & $5,66^{\mathrm{c}}$ & $6,03^{\mathrm{b}}$ & $3,61^{\mathrm{c}}$ & $4,37^{\mathrm{c}}$ & $1,71^{\mathrm{c}}$ \\
\hline MG & 5,76 & 6,97 & 6,22 & 6,57 & 6,71 & 5,61 & 6,09 & 3,03 \\
DMS & 1,20 & 0,91 & 1,06 & 1,01 & 1,06 & 1,28 & 1,03 & 0,68 \\
CV $(\%)$ & 34,82 & 21,81 & 28,54 & 25,88 & 26,54 & 38,32 & 28,27 & 37,49 \\
Fcal & $17,52^{* *}$ & $4,83^{* *}$ & $24,98^{* *}$ & $8,89^{* *}$ & $4,60^{* *}$ & $17,71^{* *}$ & $20,72^{* *}$ & $31,94^{* *}$ \\
\hline
\end{tabular}

MG - Media geral; DMS - Desvio médio significativo; CV - Coeficiente de variação; Fcal - F calculado. Médias seguidas da mesma letra, na coluna, não diferem estaticamente a $5 \%$ de probabilidade pelo teste de Tukey; ** - significativo a $1 \%$ de probabilidade pelo teste F.

A figura 1 apresenta os índices de aceitabilidade para as diferentes formulações de iogurtes de tapioca. Observa-se que os iogurtes padrão e o formulado com $7 \%$ de tapioca obtiveram índices de aceitabilidade superiores a 70\%. Segundo Teixeira et al. (1987), para que um produto seja considerado como aceito, em termos de suas propriedades sensoriais, é necessário que obtenha um índice de aceitabilidade de, no mínimo, 70\%. Levando-se em consideração o índice de aceitabilidade dos iogurtes de tapioca, apenas a formulação com $7 \%$ apresentou potencial mercadológico, podendo ser, ou não, viável comercialmente, necessitando de estudos mais aprofundados a respeito.

Figura 1 - Índices de aceitabilidade dos iogurtes de

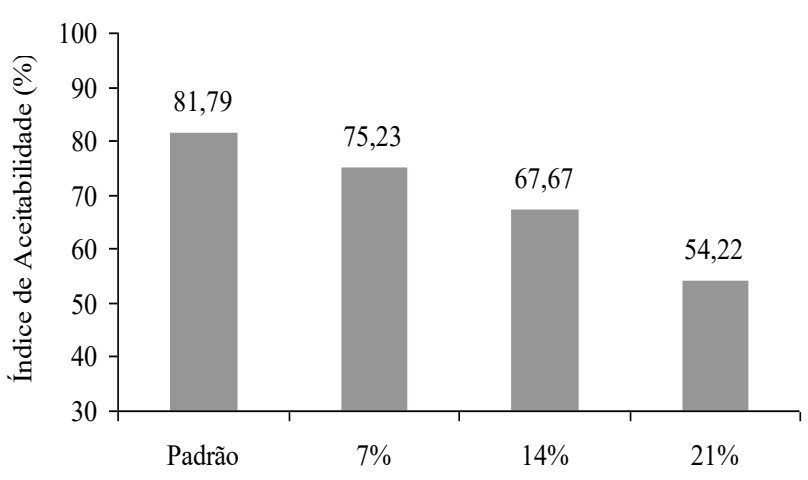

tapioca.

Observações similares foram encontradas por Oliveira et al. (2008) ao desenvolverem iogurtes 
com diferentes concentrações de polpa de araticum $(0 ; 12,5 ; 25$ e $50 \%)$. Os autores evidenciaram índices de aceitabilidade variando de 77,78 a $62,22 \%$, com as formulações contendo as maiores concentrações de araticum apresentando índices de aceitabilidade inferiores a $70 \%$.

\section{CONCLUSÃO}

A elaboração de iogurtes de tapioca mostrou-se sensorialmente viável apenas na concentração de $7 \%$, apresentando características nutricionais, físicas e químicas mais próximas ao iogurte natural. Sugerem-se novos estudos com ajustes de formulação e novos ensaios sensoriais para avaliar o real potencial mercadológico do iogurte de tapioca.

\section{REFERÊNCIAS BIBLIOGRÁFICAS}

AOAC. Association of Official Analytical Chemists. Official Methods of Analysis. 18th ed, 3th Revisão, USA: Washington, 2010. 1094p.

AMERICAN PUBLIC HEALTH ASSOCIATION (APHA). Compendium of methods for the microbiological examination of foods. 4th ed. Washington: APHA, 2001. $676 \mathrm{p}$.

BADARÓ, A.C.L.; ARAÚJO, T.F.; CARVALHO, A.F. Análise da contaminação microbiológica, mesófilos proteolíticos e lactofermentadores do leite cru comercializado no município de Ipatinga. Revista do Instituto de Laticínio Cândido Tostes, v.62, n.357, p.293-299, 2007.

BORGES, K.C.; MEDEIROS, A.C.L.; CORREIA, R.T.P. Iogurte de leite de búfala sabor cajá (Spondias lutea L.): caracterização físico-química e aceitação sensorial entre indivíduos de 11 a 16 anos. Alimentos e Nutrição, v.20, n.2, p.295-300, 2009.

BRASIL. Ministério da Saúde. Agência Nacional de Vigilância Sanitária - ANVISA. Rotulagem nutricional obrigatória: manual de orientação às indústrias de Alimentos. 2a Versão. Brasília: Mistério da Saúde/Universidade de Brasília, Brasília, DF, 2005. 44p.

BRASIL. Ministério da Agricultura, Pecuária e Abastecimento (MAPA). Instrução Normativa n.46, de 23 de outubro de 2007. Aprova o Regulamento Técnico de Identidade e Qualidade de Leites Fermentados. Diário Oficial [da] República Federativa do Brasil, Brasília, 24 out. 2007.

BRASIL. Ministério da Agricultura, Pecuária e Abastecimento. Instrução Normativa n. 62 de 29 de dezembro de 2011. Regulamento técnico de produção, identidade e qualidade de leite tipo A. Diário Oficial [da] República Federativa do Brasil, Brasília, 29 dez. 2011.

BRAGA, A.C.C.; ASSIS NETO, E.F.; VILHENA, M.J.V. Elaboração e caracterização de iogurtes adicionados de polpa e de xarope de mangostão (Garcinia mangostana L.). Revista Brasileira de Produtos Agroindustriais, v.14, n.1, p.77-84, 2012.

CAVALCANTE, J.M.; MORAIS, A.C.S.; RODRIGUES, M.C.P. Efeito da adição de amêndoas da castanha de caju nas propriedades sensoriais do iogurte adoçado com mel.
Revista Brasileira de Tecnologia Agroindustrial, v.3, n.1, p.1-14, 2009.

COSTA, G.N.S.; MENDES, M.F.; ARAUJO, I.O.; PEREIRA, C.S.S. Desenvolvimento de um iogurte sabor juçaí (Euterpe edulis Martius): avaliação físico-química e sensorial. Revista Eletrônica TECCEN, v.5, n.2 p.43-58, 2012.

DUTCOSKY, S.D. Análise sensorial de alimentos. $3^{\mathrm{a}}$ ed. $\mathrm{Cu}-$ ritiba-PR: Editora Universitária Champagnat, 2011. 426p.

FERREIRA, C.L.L.F.; MALTA, H.L.; DIAS, A.S.; GUIMARÃES, A.; JACOB, F.E.; CUNHA, R.M.; CARELI, R.T.; PEREIRA, S.; FERREIRA, S.E.R. Verificação da qualidade físico-química e microbiológica de alguns iogurtes vendidos na região de Viçosa. Revista do Instituto de Laticínios Cândido Tostes, v.56, n.321, p.152-158, 2001.

FOLCH, J.; LEES, M.; SLOANEY, G.H. A simple method for the isolation and purification of total lipids from animal tissues. Journal of Biological Chemistry, v.226, n.1, p.497509, 1957.

FREITAS, M.S.; NASCIMENTO, I.R.; VIEIRA, L.A. Fabricação de iogurte saborizado com mel: alternativa de agregação de valor aos produtos da agricultura familiar em Porto da Folha-SE. Revista Brasileira de Produtos Agroindustriais, v.14, n.2, p.191-195, 2012.

GULARTE, M.A. Análise sensorial. Pelotas: Ed. Universitária da UFPEL, 2009. 66p.

INSTITUTO ADOLFO LUTZ. Normas analíticas, métodos químicos e físicos para análises de alimentos. $4^{\mathrm{a}}$ ed. $1^{\mathrm{a}} \mathrm{ed}$. Digital, São Paulo 2008. 1020p.

JAEGER, S.R. Non-sensory factors in sensory science research. Food Quality and Preference, v.17, n.1-2, p.132144, 2006.

LOURES, M.M.R.; MINIM, V.P.R.; CERESINO, E.B.; CARNEIRO, R.C.; MINIM, L.A. Análise descritiva por ordenação na caracterização sensorial de iogurte diet sabor morango enriquecido com concentrado protéico do soro. Semina: Ciências Agrárias, v.31, n.3, p.661-668, 2010.

MANTOVANI, D.; CORAZZA, M.L.; CARDOZO FILHO, L.; COSTA, S.C. Elaboração de iogurte com diferentes concentrações de sólidos totais, análise físico-química e perfil da textura. Revista Brasileira de Tecnologia Agroindustrial, v.6, n.1, p.680-687, 2012.

MATHIAS, T.R.S.; CARVALHO JUNIOR, I.C.; CARVALHO, C.W.P.; SÉRVULO, E.F.C. Rheological characterization of coffeeflavored yogurt with different types of thickener. Alimentos e Nutrição, v.22, n.4, p.521-529, 2011.

MESQUITA, R.V.S.C.; FIGUEIREDO NETO, A.; TEIXEIRA, F.; SILVA, V.O. Elaboração, análise físico-química e aceitação do iogurte com adição do tamarindo "doce" (Tamarindus indica L.). Revista Brasileira de Produtos Agroindustriais, v.14, n.4, p.381-387, 2012.

MINIM, V.P.R. Análise sensorial: estudos com consumidores. Viçosa: Ed. Universitária da UFV, 2006. 225 p.

OLIVEIRA, K.A.M.; RIBEIRO, L.S.; OLIVEIRA, G.V.; PEREIRA, J.M.A.T.K.; MENDONÇA, R.C.S.; ASSUMPÇÃO, C.F. Desenvolvimento de formulação de iogurte de araticum e estudo da aceitação sensorial. Alimentos e Nutrição, v.19, n.3, p.277-281, 2008. 
OLIVEIRA, P.D.; LIMA, S.C.G.; LOURENÇO JÚNIOR, J.B.; ARAÚJO, E.A.F. Avaliação sensorial de iogurte de açaí (Euterpe oleracea Mart) tipo "sundae". Revista do Instituto de Laticínios Cândido Tostes, v.66, n.380, p.5-10, 2011.

PRECI, D.; CICHOSKI, A.J.; VALDUGA, A.T.; OLIVEIRA, D.; VALDUGA, E.; TREICHEL, H.; TONIAZZO, G.; CANSIAN, R.L. Desenvolvimento de iogurte light com extrato de erva-mate (Ilex paraguariensis St. Hil) e adição de probióticos. Alimentos e Nutrição, v.22, n.1, p.27-38, 2011.

QUEIROGA, R.C.R.E.; SOUSA, Y.R.F.; SILVA, M.G.F.; OLIVEIRA, M.E.G.; SOUSA, H.M.H.; OLIVEIRA,

C.E.V. Elaboração de iogurte com leite caprino e geleia de frutas tropicais. Revista do Instituto Adolfo Lutz, v.70, n.4, p.489-496, 2011.

QUEIROZ, H.G.S.; SAMPAIO NETA, N.A.; PINTO, R.S.; RODRIGUES, M.C.P.; COSTA, J.M.C. Avaliação da qualidade físico-química e microbiológica de sorvetes do tipo tapioca. Revista Ciência Agronômica, v.40, n.1, p.60-65, 2009.

ROCHA, C.; COBUCCI, R.M.A.; MAITAN, V.R.; SILVA, O.C. Elaboração e avaliação de iogurte sabor frutos do cerrado. Boletim do Centro de Pesquisa de Processamento de Alimentos, v.26, n.2, p.255-266, 2008.

SCHIMIDT, C.A.P.; PEREIRA, C.; ANJOS, G.; LUCAS, S.D.M. Formulação e avaliação sensorial hedônica de iogurte com polpa de acerola. Revista Eletrônica Científica Inovação e Tecnologia, v.1, n.5, p.10-14, 2012.

TEIXEIRA, E.; MEINERT, E.; BARBETTA, P.A. Análise sensorial de alimentos. Florianópolis: Ed. Universitária da UFSC, 1987. 180p. 